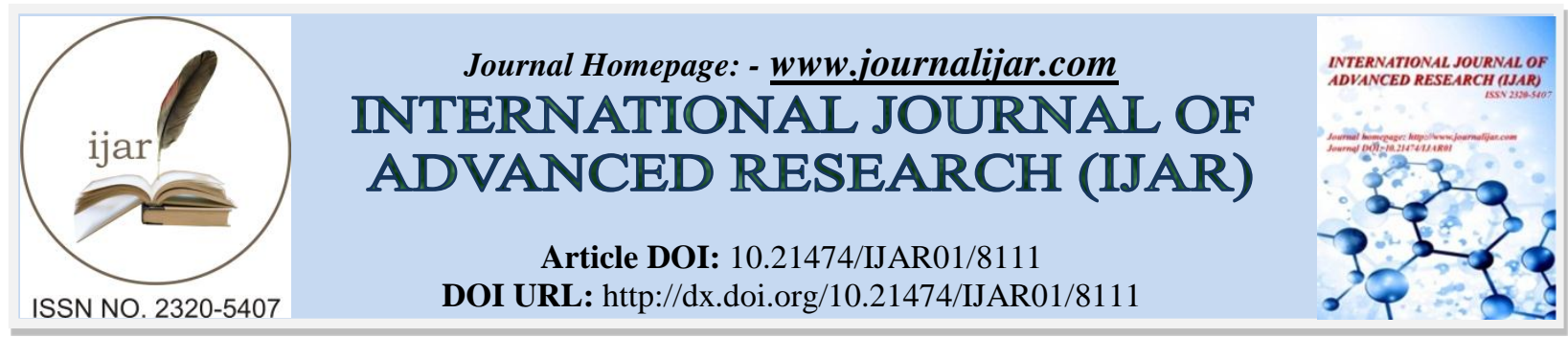

RESEARCH ARTICLE

\title{
DEPRESSION - AN EQUAL OPPORTUNISTIC KILLER.
}

\author{
Amita Charak. \\ Department of Psychology, Hans Raj Mahila Maha Vidyalaya, Jalandhar-144008.
}

\section{Manuscript Info}

Manuscript History

Received: 01 October 2018

Final Accepted: 03 November 2018

Published: December 2018

Keywords:

Depression, Dysthymia, Insomnia, Chiropractic treatments.
Abstract

Depression has been recognized as a distinct pathological entity from early Egyptian times. Depression is the most common psychiatric disorder. Major depression is a mood disorder characterized by a sense of paucity, melancholia, nihilist, decreased activity, worrywart, anhedonia and sadness. Each year, more than 100 million people worldwide develop clinical depression. It is estimated that during lifetime $8 \%-20 \%$ of the general population experience at least one clinically significant episode of depression. Depressive disorder has significant potential morbidity and mortality. Major depression causes the fourth-highest burden of disease among all medical diseases. It is expected to rise to second place, preceded only by cardiovascular disease. Depression severely disrupts and adversely alter the life of an individual, sometimes to such an extent that suicide is result or attempted. Suicide is the second leading cause of death in individuals aged 20-35 years. Depressive disorder is a major factor in around 50\% of these deaths. The search for an extended understanding of the causes of depression, and for the development of additional effective treatments is highly significant. Clinical and pre-clinical studies suggest stress is a key mediator in the pathophysiology of depression.

Copy Right, IJAR, 2018,. All rights reserved.

\section{Introduction:-}

Depression will become the second biggest illness in terms of morbidity by next decade in the world as estimated by World Health Organization, already one out of every five women, and twelve men have depression. Earlier it was thought that only adults got depressed but new studies also showed that five percent of the teenagers and two percent of school going children also suffer from depression, and most of the time it goes unidentified. Depression has been the commonest reason for which the people went to seek the advice of psychologist /psychiatrist1-2. People still believe that depression is because of some kind of weakness in personality. Most of the myths were formulated by quacks, faith healers, or unqualified counselors, and non-medical experts for their own vested interest, and largely by an unaware society. An increased awareness, and approach to psychiatrists, has been the main reason for the increase in number of patients and not necessarily an increase in prevalence. With newer and better facilities and medication, treating depression has become easier, and most people respond very well to treatment, and return to normal functioning very soon after receiving the treatment3.

Corresponding Author:-Amita Charak.

Address:-Department of Psychology, Hans Raj Mahila Maha Vidyalaya, Jalandhar-144008. 


\section{Depression and its types:}

Just like many other illnesses, Depression has varied forms:

1. Major depression is manifested by the combination of symptoms that intervenes in the capacity to eat, work, sleep and enjoying pleasurable games. These episodes of depression can occur once, twice or several times in a lifetime of an individual causing disableness.

2. Dysthymia, a low degree type of depression. This type of depression involves long-term, chronic symptoms that may not allow you to enjoy the life to the fullest. Thus, keeping you away from feeling comfortable. On certain occasion people with dysthymia may experience major depressive episodes.

3. Manic-depressive or bipolar is not nearly as prevalent as other forms of depressive illnesses. It involves intervals of elation and depression. Sometimes the mood switches are dramatic and rapid. When in the depressed cycle, one can have any or all other the symptoms of a depressive illness. Mania often affects thinking, judgment, and social behaviour in ways that may cause serious problems and embarrassment4-5.

\section{Prevalence - World scenario and Indian scenario \\ Indian:}

Depression is the most common psychiatric disorder reported in most of the community based studies. It is also reported as one of the most common psychiatric disorder in outpatient clinic population and in subjects seen in various medical and surgical setting. It is also reported to be the most common psychiatric disorder in elderly subjects across various settings. Studies from India have also shown that life events during the period preceding the onset of depression play a major role in depression. Studies on women have also shown the importance of identifying risk factors like interpersonal conflicts, marital disharmony and sexual coercion6-7.

There is also a need to study the course of depressive disorders in India so as to determine the need and duration of continuation treatment. Studies should also evaluate the cost-effective models of treatment which can be easily used in the primary care setting to effectively treat depression8.

\section{Symptoms of depression:}

Not everyone who is in the state of irritable mood or depression experience each symptom. Some may experience many symptoms, some few. Moreover, the severity of symptoms may vary with individuals 9-12.

\section{Symptoms of Depression:}

1. Dull mood, anxiousness and Persistent sadness.

2. Feeling of hopelessness, Pessimism.

3. Feeling of guilt, worthlessness, helplessness.

4. Loss of interest or pleasurable activities that an individual once enjoyed the most.

5. Loss of appetite and weight loss.

6. Overeating and weight gain.

7. Insomnia, early-morning awakening or oversleeping.

8. Fatigue, Decreased energy, being slowed down.

9. Thoughts of suicide or suicide attempts, deaths.

10. Irritability, restlessness.

11. Difficulty in remembering, concentrating and decisions making.

12. Physical symptoms that may be present after the treatment, such as headaches, digestive disorders and immense pain.

\section{Causes of Depression - Genetic component and different environmental factors.}

\section{Genetic Causes of Depression}

Most of the published genetic association studies of mood disorders have focused on functional polymorphisms (DNA sequence variations that alter the expression and/or functioning of the gene product) in the loci encoding the serotonin transporter (SLC6A4), serotonin 2A receptor (5HTR2A), tyrosine hydroxylase (TH) (the limiting enzyme for dopamine synthesis), tryptophan hydroxylase 1 (TPH1) (serotonin synthesis), and catechol-o-methyltransferase (COMT) (dopamine catabolism). It has long been known that depressive illnesses can run in families, until recently it was not fully known whether people inherited a susceptibility to this disease or the culprit was something else like environment. Researchers were able to demonstrate that to some extent depressive illnesses can be inherited. This means that if we have close family members undergoing clinical depression, we may also have the tendency to develop the illness. This does not mean that we are destined to become depressed14-15. 
Bipolar disorder has a strong genetic influence. People with bipolar disorder, approximately $50 \%$ of them have a parent with a history of clinical depression. Whenever a mother or father has bipolar disorder, their child will have a $25 \%$ chance of developing some type of clinical depressive illness. If both parents have bipolar disorder, the chances of their children also developing bipolar disorder is between $50 \%$ and $75 \%$. Siblings of those with bipolar disorder may be 8 to 18 times more likely to develop bipolar disorder, and 2 to 10 times more likely to develop major depressive disorder than others with no such brothers and sisters16.

\section{Twin Studies:}

what we know about the genetic influence of clinical depression is mostly based on research that has been carried out on identical twins. Identical twins are very helpful to researchers because both of them have the exact same genetic code. Some studies had suggested that when one identical twin becomes depressed the other will also develop clinical depression approximately $76 \%$ of the time. When these identical twins were raised away from each other, they will both become depressed about $67 \%$ of the time. Because both twins become depressed at such a high rate, this means that there is a strong genetic influence. If it happened that means clinical depression would likely to be entirely genetic. However, the rate of both identical twins developing depression is not closer to $100 \%$ this suggest that might be there are some other factors responsible depression. These may include environmental factors such as exposure to substances, childhood experiences, current stressors, traumatic events, medical illnesses, etc 1719.

\section{Environmental Causes of Depression}

Environmental causes of depression include events such as stress, traumatic events and childhood difficulties. These are events that can happen to anyone and they happen during our everyday lives. They are considered factors that are outside of us. Some researchers refer to these events as sociological or psychosocial factors because they are a "meeting" or "combination" of events that happen in society and the function and workings of the human mind. Researchers have known for some time that the experiences (events) we have in our lives can and do affect our mental health. Thoughts, emotions and behaviors of people are influenced by the prior experiences in their lives. These experiences can include past relationships, childhood development and past crises. The key to development of clinical depression in some people seems to be how they react to the various environmental causes or factors in their everyday lives 20 .

\section{Childhood Difficulties:}

Chances of higher rates of clinical depression are high in peoples with severe difficulties in their childhood. The most common childhood difficulties include sexual, emotional, or physical abuse, dysfunctional upbringing, parental separation, and mental illness in one or both of the parents. One of the most difficult emotional events for a child to endure is the separation or death of a parent before the age of eleven. Children that have experienced these events demonstrate a higher probability of developing depression21-22.

\section{Stress:}

There appears to be a very complex relationship between stressful situations, the reaction of the individual's mind and body to stress, and the development of clinical depression. Most researchers believe that for some people there is a direct relationship between a stressful event and the development of depression. What is interesting to note is that this stress can be negative or positive. Examples of negative stress are loss of a loved one, loss of a job, loss of a relationship and divorce. Examples of positive stress are planning for a wedding, preparing for a new job, and moving to a new city. Both negative and positive stress from environmental events can precede the development of depression 23 .

\section{Traumatic Events:}

It is a fact that many people have experienced a traumatic event prior to developing depression. Traumatic events in the lives of people include loss of a loved one, a serious medical illness, the end of a marriage or significant financial loss. These types of events can destroy the sense of control and stability in a person's life, often leading to emotional distress 24 .

\section{Noise Pollution:}

Noise pollution has been linked to aggression, hypertension, increased stress levels, tinnitus, hearing loss and disruptions in sleep. Specifically, tinnitus is linked to severe depression, panic attacks and forgetfulness. Continual exposure to noise pollution has also been linked to cardiovascular disease and increased blood pressure. A person 
with possible depressive tendencies will become even more susceptible to depression with continual, prolonged exposure to noise pollution25.

\title{
Electrical Pollution:
}

We are constantly surrounded by radio waves everywhere we go. Much of the electrical equipment we use works off of radio waves and these radio waves have been found to induce depression and rage. The exact causes as to why are not yet known and unlike other types of environmental causes of depression, electrical pollution cannot be seen, heard, tasted, or felt. But, it does have a negative effect on our mind and body 26.

\section{Natural and Catastrophic Disasters:}

Natural and catastrophic disasters, such as hurricanes, earthquakes, or fires, and even manmade disasters such as bombings and war can push an already susceptible person into a severe Major Depression. The National Centre for Environmental Health has found that people, who normally would not be a candidate for depression, can become depressed after major life altering episodes, such as their house being destroyed in a natural disaster27-28.

\section{Synthetic Chemicals:}

Every day we take in synthetic chemicals from all over. From preservatives, additives and hormones that are found and added to so many of our foods, pesticides that are sprayed and air and water pollution as well. Studies have shown that air and water pollution alone can cause cancer and other diseases. Synthetic chemicals and pollutants are now being more closely looked at as a link to depression and Major Depressive episodes29.

\section{Treatment}

Mild depression can be effectively treated with either medication or psychotherapy. Moderate to severe depression may require an approach combining medication and psychotherapy30.

\begin{abstract}
Alternative Treatments for Depression
There is no evidence that any alternative treatment or home remedy is effective in treating moderate to severe depression. However, some people with mild depression may find benefit from home remedies or alternative therapies like yoga, massage therapy, Acupuncture, Aromatherapy, Biofeedback, Chiropractic treatments, Guided imagery, Herbal remedies, Hypnosis, Massage therapy, Meditation, Relaxation, Yoga, etc 31.
\end{abstract}

Different forms of exercise can lower stress level, relax you, and reduce depression. Exercise can also increase your energy, balance, and flexibility. In general, exercise is a safe, effective, and easy way to improve your well-being.

\section{Conclusion:-}

Depression is a serious medical condition and a profound public health concern. Although the development of depression is likely due to a combination of factors, understanding the various effects, possible triggers, and treatments of the disorder is essential for promoting the well being of affected individuals. There is also a need to study the course of depressive disorders present in the world so as to determine the need and duration of continuation treatment. Studies should also evaluate the cost-effective models of treatment which can be easily used in the primary care setting to effectively treat depression.

\section{Acknowledgement:-}

The author is thankful to Sorabh Singh Sambyal PhD Research Scholar (Microbiology) Jaipur National University, Jaipur, Rajasthan for his encouragement and valuable suggestions in writing this manuscript.

\section{References:-}

1. Kessler R.C., McGonagle K.A., Zhao S., et al., Lifetime and 12-month prevalence of DSM-IIIR psychiatric disorders in the United States, Results from the National Comorbidity Survey Arch Gen Psychiatry, 51, 8-19, (2003)

2. Robins L., Regier D., Psychiatric Disorders in America, New York: Free Press (2004)

3. Depression Guideline Panel. Depression in Primary Care: Volume 1. Detection and Diagnosis Clinical Practice Guideline, Number 5. Rockville, Maryland: U.S Department of Health and Human Services; AHCPR No. 93 0550 (2001)

4. Katon W. The epidemiology of depression in medical care, Int J Psychiatry Med, 17, 93-112, (2006)

5. Judd L.L., The clinical course of unipolar major depressive disorders Arch Gen Psychiatry, 54, 989-991, (2008) 
6. Greenberg P.E., Stiglin L.E., Finkelstein S.N., et al., The economic burden of depression in 1990, J Clan Psychiatry, 54, 405-418, (2009)

7. Blair-West G.W., Mellsop G.W. and Eyeson-Annan M.L., Down-rating lifetime suicide risk in major depression, Acta Psychiatr Scand, 95, 259-263, (2010)

8. Harris E.C., Barraclough B., Suicide as an outcome for mental disorders, A meta-analysis Br J Psychiatry, 170, 205-228, (2001)

9. Consensus Development Panel, NIMH/NIH Consensus Development Conference statement Mood disorders: pharmacologic prevention of recurrences, Am J Psychiatry, 142, 469-476, (2003)

10. Pennix B.W., Guralnik J.M., Ferrucci L, et al., Depressive symptoms and physical decline in communitydwelling older persons JAMA, 276, 1720-1726, (2007)

11. American Psychiatric Association, Diagnostic and Statistical Manual of Mental Disorders, Fourth Edition Washington, DC: American Psychiatric Association (2000)

12. Wells K.B., Stewart A., Hays R.D. et al., The functioning and well-being of depressed patients Results from the Medical Outcomes Study, JAMA, 262, 914-919, (2002)

13. Howland R., General health, health care utilization, and medical comorbidity in dysthymia, Int J Psychiatry Med 23, 211-238, (2005)

14. Wells K.B., Burnam M.A., Rogers W, et al., The course of depression in adult outpatients Results from the Medical Outcomes Study, Arch Gen Psychiatry, 49, 788-794, (2002)

15. Williams J.W. Jr, Kerber C.A., Mulrow C.D., et al., Depressive disorders in primary care: prevalence, functional disability and identification, J Gen Intern Med., 10, 7-12, (2008)

16. Wagner R., Burns B.J., Yarnall K., Sigmon A., Walker R. and Gaynes B.N., Minor depression in family practice: functional morbidity, comorbidity, service utilization and outcomes, Psychol Med., 30(6), 1377-1390, (2000)

17. Cooper-Patrick L., Crum R.M., Ford D.E., Characteristics of patients with major depression who received care in general medical and specialty mental health settings, Med Care, 32, 15-24, (2009)

18. Paykel E. and Priest R., Recognition and management of depression in general practice, consensus statement, BMJ 305, 1198-1202, (2002)

19. Simon G.E., Von Korff M. and Durham M.L., Predictors of outpatient mental health utilization by primary care patients in a health maintenance organization, Am J Psychiatry, 151, 908-913, (2004)

20. Song F., Freemantle N. and Sheldon T.A., et al., Selective serotonin reuptake inhibitors: meta-analysis of efficacy and acceptability, BMJ, 306, 683-687, (2006)

21. Pincus H.A., Tanielian T.L. and Marcus S.C., et al., Prescribing trends in psychotropic medications, primary care, psychiatry and other medical specialities, JAMA, 279, 526-531, (2007)

22. Simon G.E. and Von Korff M., Recognition, management, and outcomes of depression in primary care, Arch Fam Med., 4, 99-105, (2007)

23. Kessler R.C., Nelson C.B., McGongale K.A., Liu J., Swartz M. and Blazer DG., Comorbidity of DSMIIIR major depressive disorder in the general population, Results from the US National Comorbidity Survey, $\mathrm{Br} J$ Psychiatry, 168, 17-30, (2006)

24. Regier D.A., Narrow W.E., Rae D.S., Manderscheid R.W., Locke B.Z. and Goodwin F.K., The de facto US mental and addictive disorders service system, Epidemiologic catchment area prospective 1-year prevalence rates of disorders and services, Arch Gen Psychiatry, 50, 85-94, (2005)

25. Klinkman M.S., Competing demands in psychosocial care, A model for the identification and treatment of depressive disorders in primary care, Gen Hosp Psychiatry, 19, 98-111, (2001)

26. Borowsky S.J., Rubenstein L.V., Meredith L.S., Camp P., Jackson-Triche M. and Wells K.B., Who is at risk of nondetection of mental health problems in primary care, J Gen Intern Med,. 15, 381-388, (2000)

27.. Linde K., Mulrow C.D. and St. John's wort for depression, Cochrane Review, The Cochrane Library, (2008)

27. US Preventive Services Task Force. Guide to Clinical Preventive Services, 2nd ed, Alexandria, Va., International Medical Publishing, (2009)

28. Gerber P.D., Barrett J., Barrett J., Manheimer E., Whiting R. and Smith R., Recognition of depression by internists in primary care, a comparison of internist and gold standard psychiatric assessments, J Gen Intern Med,. 4, 7-13, (2003)

29. American College of Physicians, ACP-ASIM Clinical Practice Guidelines: Current and Future Projects, Available at: http://www.acponline.org/sci-policy/guidelines/projects.htm. (2009)

30. Myers J.K. and Weissman M.M., Use of a self-report symptom scale to detect depression in a community sample, Am J Psychiatry., 137, 1081-1084, (2000). 